\title{
Evaluation of Defferent Planning Systems in Regional Substainable Development using Simulation \& Gaming
}

\author{
HIDEHIKO KANAGAE \\ Tokyo Institute of Technology \\ and \\ HIDEAKI KAJI \\ SFC, Keio University \\ and \\ TOSHIYUKI KANEDA \\ Nagoya Institute of Technology
}

\begin{abstract}
The paper addresses one of a traial for evaluation that different planning systems are suitable for sustainable regional development using a simulation game PANGAEA, which facilitates professional planners' training. The concept of "sustainable development" was proclaimed at the Earth Summit, 1992, and has been widely accepted and supported by both developing and developed countries. Although it is easy to see that we need "sustainable development" approaches, we cannot pretend that it is similarly simple and straightforward to realize sustainable development processes. As a professional planning exercise for human resource development, there are four key controlling factors to achieve sustainable regional development in PANGAEA : capacity, distribution, pace, and efficiency. Although main objective of PANGAEA is planner training, it is not ordinary result but it give us a precious hint for the future that different governmental institutions as planning systems would generate better their own public investment plans toward sustainable development by running and stock of some planner training. From the point of view of local optimization in planning function, decentralized planning system might work well for keeping balance with development and environmental preservation less failure One of a result shows decentralization was suit for sustainable development under some conditions.
\end{abstract}

Keyword : sustainable development, simulation \& gaming, planning, regional development, planner training, systems dynamics modeling

\section{Introduction}

Which governmental system is better for regional sustainable development in developing countries, centralization or decentralization? In regards to our regional planning context, the 
answer would closely depend on the socio-economics and environmental levels at which the country is situated.

For the past ten or so years, the United Nations Centre for Regional Development (UNCRD) has been conducting a microcomputer-based regional planning exercise as an integral part of UNCRD's International Training Course in Regional Development Planning”. This exercise has both gaming and computer simulation components on policy formation for regional development. It serves well as an instrument to increase trainees' interest and motivation, a laboratory for applying and testing their acquired knowledge and skills, a virtual model for facilitating comprehension of world realities, as well as chances to get insights into the decision maker's predicament. The first simulation \& gaming exercise that UNCRD developed in 1984 was called "REPLEX," signifying "REgional PLanning EXercise." As in the case of REPLEX, PANGAEA enables participants to improve their behavioral skills such as negotiation and coordination, understand the complexity of the planning process, and formulate plans in rational manners supported by microcomputers. The participants also take part in role playing and gaming. In addition, the advancement of PANGAEA can be described as follows: (1) it is based on a sustainability oriented simulation model, reflecting the trade-off between development and environment, in total capacity of the nature, efficiency in resources conservation, spatial distribution and pace of development, (2) it has three alternatives in the institutional setup for planning, namely, centralized-sectorial, centralized-coordinate, and decentralized planning systems, (3) it is played in a server-client network environment, on the Internet, in particular, and (4) more user-friendly interface is provided by utilizing an Internet browser and other currently available multimedia tools. The simulation \& gaming systems included models, named PANGAEA-series ${ }^{1)}$ which were designed to deal with the sustainability at a regional development level based on a plan, especially focusing on South East Asia where the national economies are now growing rapidly.

Discussions of the effects of institutions to generate their own public investment plans on regional sustainable development under different governmental systems are one of the most important features of PANGAEA. In order to get a "hands-on" feeling from the point of view of regional planning professionals, the computer simulation engine of PANGAEA requires system dynamics modeling which consists of multiple feedback causal loops among multisectors and multi-regions. Concerning setting targets, controlling policies, allocating investment, various kinds of actors, such as the central and local governments and citizens, are in the modeled society. An interaction system of each role has to be modeled. A complex" man-machine" simulation \& gaming modeling approach can be effective.

The authors held many simulation \& gaming session on many occasions in many places to held in the development and running of PANGAEA, for example, about 150 international 
participants under three controlled cases of governmental systems (two cases of centralization and one case of decentralization) on November 1996 at Okinawa University, Japan.

The paper aims to clarify the framework of the simulation \& gaming model of PANGAEA, and to confirm the effectiveness of the results of actual simulation \& gaming under the different governmental institusions as planning systems.

\section{Objective of Sustainable Regional Development}

The conventional approaches to regional development have been mainly aimed at the economic growth of a country. It was understood that the economic growth represented by GDP naturally brought a high level of income to the country's people and thus led to the improvement of people's standard of living, which may be said to be the final objective of regional development. However, it was noted that the maximization of GDP did not always lead to the heighest income level on an individual basis, particularly in cases where wealth was concentrated on a limited area or group due to a biased distribution of benefits brought about by the increase in GDP. Therefore, the major concern in conventional regional development was to minimize regional disparities through a balanced development throughout a given country. Thus, the two objectives were contradictive in targeting conventional regional development as follows :

$\begin{array}{ccc}\text { Aggregated Objective } & \text { GDP } & \text { Maximize } \\ \text { Disaggregated Objective } & 1 / \mathrm{N} \Sigma \mathrm{Ii} & \text { Maximize } \\ \text { Where } \quad \mathrm{N}=\Sigma \mathrm{i} & & \end{array}$

\section{Ii : Income level of individual i}

Sustainable regional development, however, requires the inclusion of environmental sustainability in its objective, in addition to higher economic growth. Haq (1995) pointed out that ; the new models of sustainable development must be based on at least four guideline principles. First, the models must place people at the centre. Second, the new models of development must be based on environmentally sound technologies, particularly in energy. Third, powerful incentives are needed for economic agents to reflect the correct value of the environment in all decision making. Fourth, sustainable development models must be participatory and community based.

Therefore, the objective function of sustainable regional development can be formulated as follow :

$$
\begin{aligned}
\mathrm{S}=\mathrm{s}(\mathrm{P}, \mathrm{E}) \rightarrow & \text { Maximize } \\
\text { where } & \mathrm{S}: \text { Sustainable growth } \\
& \mathrm{P}: \text { Production (GDP) } \\
& \mathrm{E}: \text { Environmental quality (Social capital) }
\end{aligned}
$$


With regard to the disaggregated individual goal, the objective function of standard of living in the conventional approach was replaced with quality of life which consists of income level and environmental amenities in daily life, both of which are the distributed amount of production and environment quality to individuals respectively.

$$
\begin{aligned}
\Sigma \mathrm{Qi}=\mathrm{Q}(\mathrm{Ii}, \mathrm{Ai}) \rightarrow \quad & \text { Maximize } \\
\text { where } & \text { Qi : Quality of life } \\
& \text { Ii : Income level (Per capita) } \\
& \mathrm{Ai}: \text { Amenity (Social overhead capital) }
\end{aligned}
$$

Needles to say, the same problem of unequal or skewed distribution of wealth to individuals as observed in the conventional objectives of the aggregated and disaggregated individual objective formulae exists herein. Therefore, balanced development between regions is again essential for sustainable development.

These formulae of the objective function for sustainable regional development need further clarification. The measurement of environmental quality $\mathrm{E}$ includes three factors such as infrastructural capital stock, natural resources, and environmental pollution that are produced by human activities.

$$
\begin{aligned}
\mathrm{E}=\mathrm{E}(\mathrm{C}, \mathrm{N}, \mathrm{L}) & \\
\text { where } & \mathrm{E}: \text { Environment Quality } \\
& \mathrm{C}: \text { Capital Stock (Artificial Environment) } \\
& \mathrm{N}: \text { Natural Resources (Natural Environment) } \\
& \mathrm{L}: \text { Environmental Pollution (Externality) }
\end{aligned}
$$

Obviously, these three factors of environmental quality are closely interrelated to productive activities. As shown in Figur 1, industrial production depends on capital stock, such as water supply, electricity, and roads, and it consumes natural resources. It also generates pollution in the process. In other words, there is a trade-off relation between production and environmental quality that makes Pareto optimality difficult.

Production and three factors of environmental quality can be controlled by public and private investments. Here in this paper, discussion will concentrate on public investment only, which is roughly classified into four types:

(a) Investment in production includes resource saving technology and development skills to achieve minimum use of land reformed to capital stock.

(b) Investment in capital stock includes infrastructural development in general, such as electricity, water supply, road construction, railway and port construction, and irrigation and land consolidation.

(c) Investment in natural resources includes aforestation, recycling technology, land conservation, and protection of species diversity.

(d) Investment in pollution prevention includes zero emission technology, and purification 
technology.

The proportion of budget allocated to capital stock which derectly promotes production, and to natural resource conservation and pollution prevention is another trade-off choice in a given budget framework. Thus, achievement of the objective of sustainable regional development vitally dependes on the balance of allocation of public investment to these four types of investment categories.

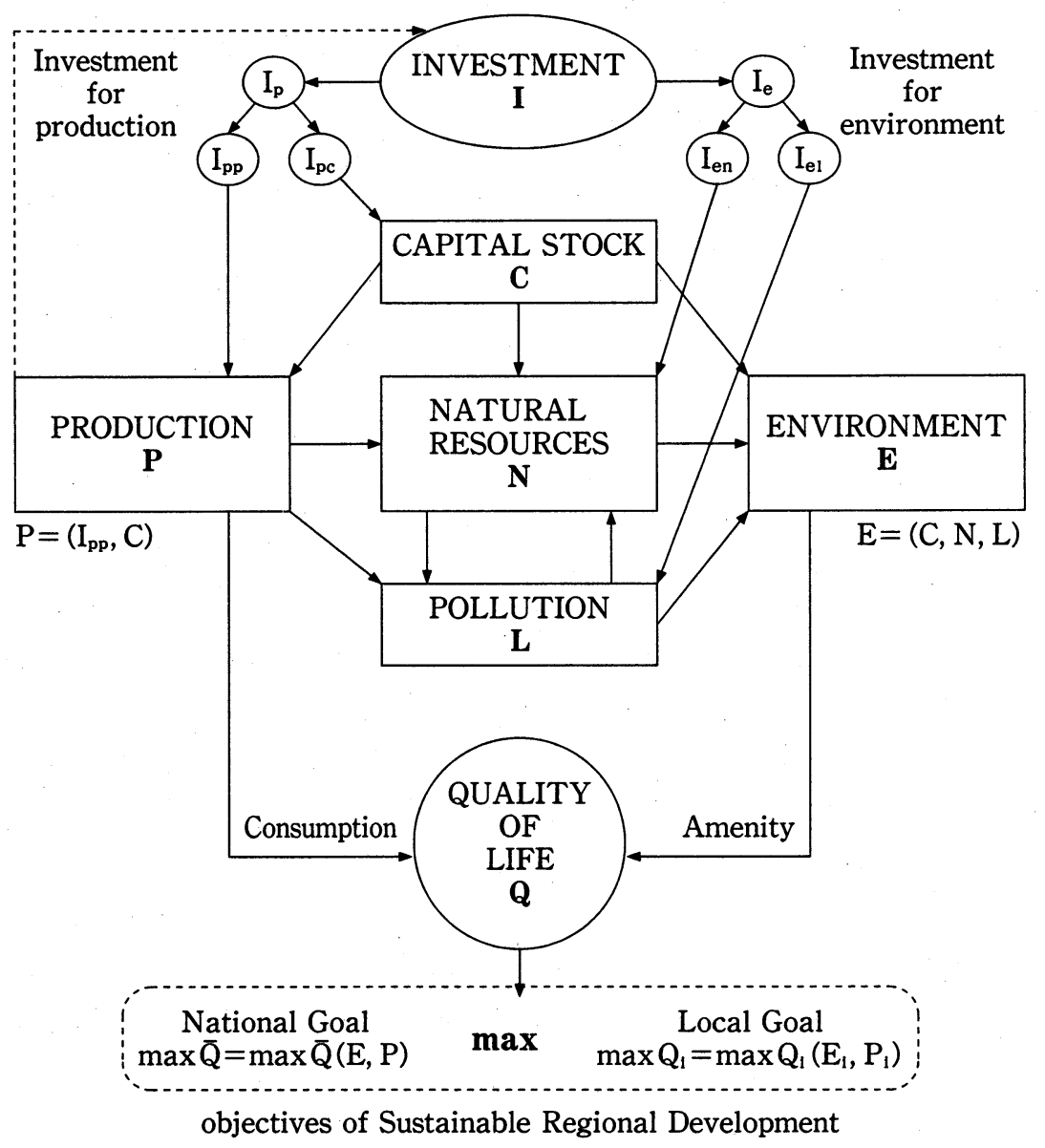

Figure 1 Four-Controlling Factors for Sustainable Regional Development

\section{Concept of sustainability}

While it is easy to see that we need "substainable development" approaches, we cannot pretend that it is similarly simple and straightforward to see sustainable development processes. We have observed growing evidences that there is a clear relationship among environmental degradation, resource depletion, poverty and the development process. There- 
fore, we need to manage the process of development, incorporating the factors that control sustainability in development.

From the viewpoint of planning, this objective function has to be converted in order to answer the question as to the extent or the degree to which development can be permitted in terms of natural resources with a limited environmental tolerance, and in what manner development should be planned and implemented. These planning demensions have been broadly divided into the four questions stated nest: (1) How much (size/volume)? (2) What (contents)? (3) Where (place)? (4) When (timing and pace)?

There are four keys controlling factors for sustainable regional, namely, capacity, distribution, pace, and efficiency. They can be caputured in the following terms. Capacity: Total development volume, beyond which development should not be attempted; Distribution: Spatial allocation of development, which contains development within the carrying capacity of the respective localities by deconcentration; Pace: Development speed, which secures the destruction pace to be slower than the regeneration pace ; and Efficiency : Energy/ resource conserving development, which enables lower consumption of energy and other resources per development input.

The total development volume, of course, is a decisive factor affecting the carrying capacity of the environment. Therefore, a balanced development input in terms of the capacity should always be considered. This balanced input applies not only to the project investments by the central and local governments but to the foreign direct investments as well.

Even though the same development volume, which is apparently within the capacity, is implemented, its effects would be totally different, depending on how it is managed in time and space as well as the resource/energy efficiency. This is a very important point for deliberating sustaiability in development planning. If the development activities were concentrated in a certain area, they would easily go beyond the carrying capacity of the environment in that specific area. If the same volume of development were properly distributed in several other areas also, the volume in each area would remain within the respective carrying capacities.

The concentration and distribution of development volume also apply to the dimension of time. If development took place at the speed surpassing the nature's regeneration pace, it would go beyond the non-recoverable level of the nature. If, on the contrary, the development pace was controlled so that the regeneration would go on in the future, sustainable development would be successfully achieved.

Another important point for environmental sustainability is resource/energy saving development. In other words, efficiency of development is in terms of energy and resource consumption. When the energy or resource consumption per unit development in smaller, 
more efficient development would be attained in the sense of sustainability.

\section{Overview of PANGAEA}

The simulation \& gaming model PANGAEA deals with a single island country, "pangaea country", with eight areas. The players will be assigned the role of developing the country as its government planners (officials) or citizens groups. This country is not simply one of the nations of the world but as a prototype of the earth itself. This "virtual" country in this simulation \& gaming is calld PANGAEA. It means that PANGAEA exists in the database and simulation \& gaming model as a virtual country. Web-based planning system of PANGAEA can play through the Internet ${ }^{1)}$ (see Figure 2).

The objective of PANAGEA is learning by doing, the planning process of the real world development in the virtual settings of gaming and the resulting socioeconomic changes simulated in a computer model world. The players are expected to learn the following aspects by the simulation \& gaming: (1) Awareness of the complexity in the regional systems dynamics; (2) Importance of integrated planning; and (3) institutional arrangements and effects of planning.
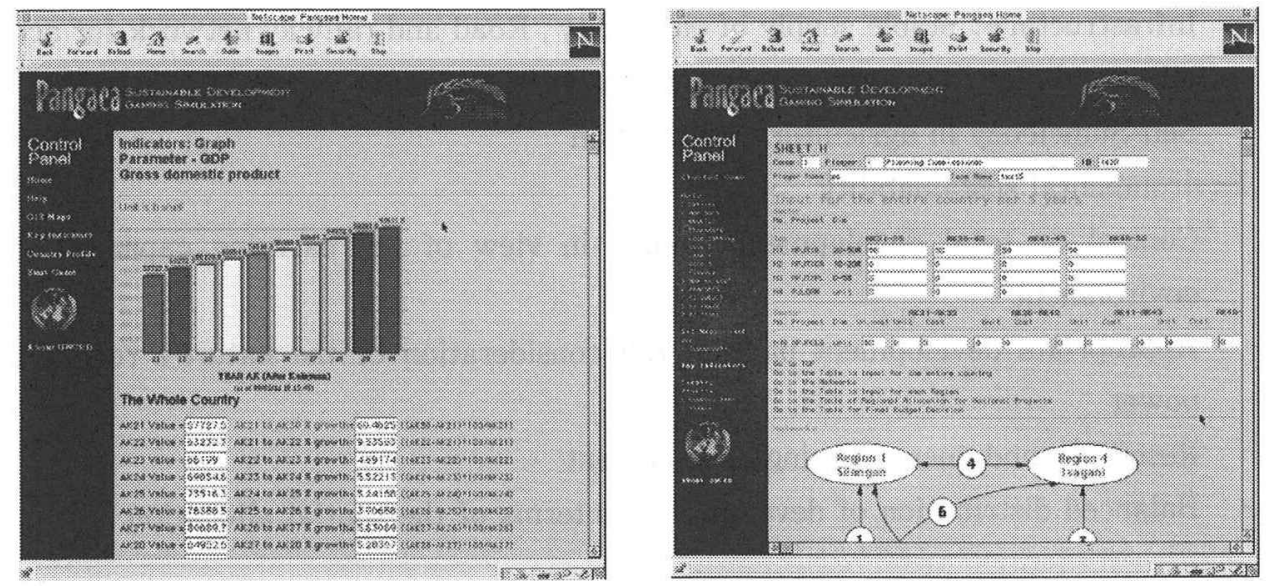

Figure 2 Web browsing pages of simulation \& gaming PANGAEA

The computer simulation model of PANAGEA, named PAN/DECS : (PANAGEA/Development and Environment Dynamics model), illustrates the changing profile of eight areas in the country (unit or district for development administration) extended over 20 years' time, with an interim review after the first 10 years. There are four regions in Pangaea shown in Figure 2 and Table 1, namely, Region 1 : Perlas ; Region 2 : Rampal ; Region 3 : Gandaria ; and Region 4 : Silao. Perlas is also the Capital Region. Each region has two areas; the one having 
the regional capital is of a concentrated urban nature and the other surrounding the former is of a suburban nature in case of (1) Perlas, and of a rural nature in the rest of the regions. The regional capital of Perlas is the capital of the country as well (Figure 3).

The administrative structure of PANGAEA has two layers, consisting of national, and regional and local levels. There are four regional governments $(1$ capital region and 3 other regions) and three local governments representing 3three regional capital cities (excluding the national capital city in the capital region).

Besides the players for the governments, citizens' groups (or NGOs) should be involved in the gaming : sometimes representing communities and sometimes as interest groups, monitoring the governments' policies and appealing their opinions to the governments fully utilizing their voting power.

In PANGAEA, the projects available for development inputs are designed. Basic policies to be made by the players in formulating their plans for project investments are on economic development and environmental sustainability as listed below :

(1) Economic development

- Inducement of foreign direct investment

- Production of basic industrial meeting the domestic needs

- Tourism promotion

- Infrastructure : Stable supply of electricity ; Road and railway network for accessibility and distribution improvement; International trade port

- Self-Sufficiency in agricultural production

(2) Environmental sustainability

- Control on total development volume in view of the carrying capacity of the environment

- Appropriate development pace in full consideration of the nature's regeneration power

- Resources and energy saving development

- Balanced distribution of development in terms of the spatial allocation 
Evaluation of Defferent Planning Systems in Regional Substainable Development using Simulation \& Gaming

Table 1 PANGAEA regional profiles

\begin{tabular}{|l|c|c|c|c|}
\hline \multicolumn{1}{|c|}{ Region } & Perlas & Rampal & Gandaria & Silao \\
\hline \hline Aria (km²) & 11,695 & 34,680 & 43,006 & 35,623 \\
\hline $\begin{array}{l}\text { Population of th } \\
\text { eregion (thousand) }\end{array}$ & 25,226 & 19,470 & 22,232 & 21,053 \\
\hline Key function & $\begin{array}{c}\text { Political and } \\
\text { economical center }\end{array}$ & $\begin{array}{c}\text { Agricultural } \\
\text { center }\end{array}$ & $\begin{array}{c}\text { Cultural, academic, } \\
\text { and tourism center }\end{array}$ & $\begin{array}{c}\text { Industrial } \\
\text { center }\end{array}$ \\
\hline \hline Capital & $\begin{array}{c}\text { Silangan } \\
\text { (National Capital) }\end{array}$ & Araya & Upakarta & Isagani \\
\hline \hline Area (km²) & 590 & 4,742 & 1,498 & 1,113 \\
\hline $\begin{array}{l}\text { Population } \\
\text { the capital } \\
\text { (thousand) }\end{array}$ & 7,316 & 4,936 & 4,202 & 3,430 \\
\hline $\begin{array}{l}\text { Population } \\
\text { density }\end{array}$ & 12,400 & 2,834 & 2,805 & 3,082 \\
\hline
\end{tabular}

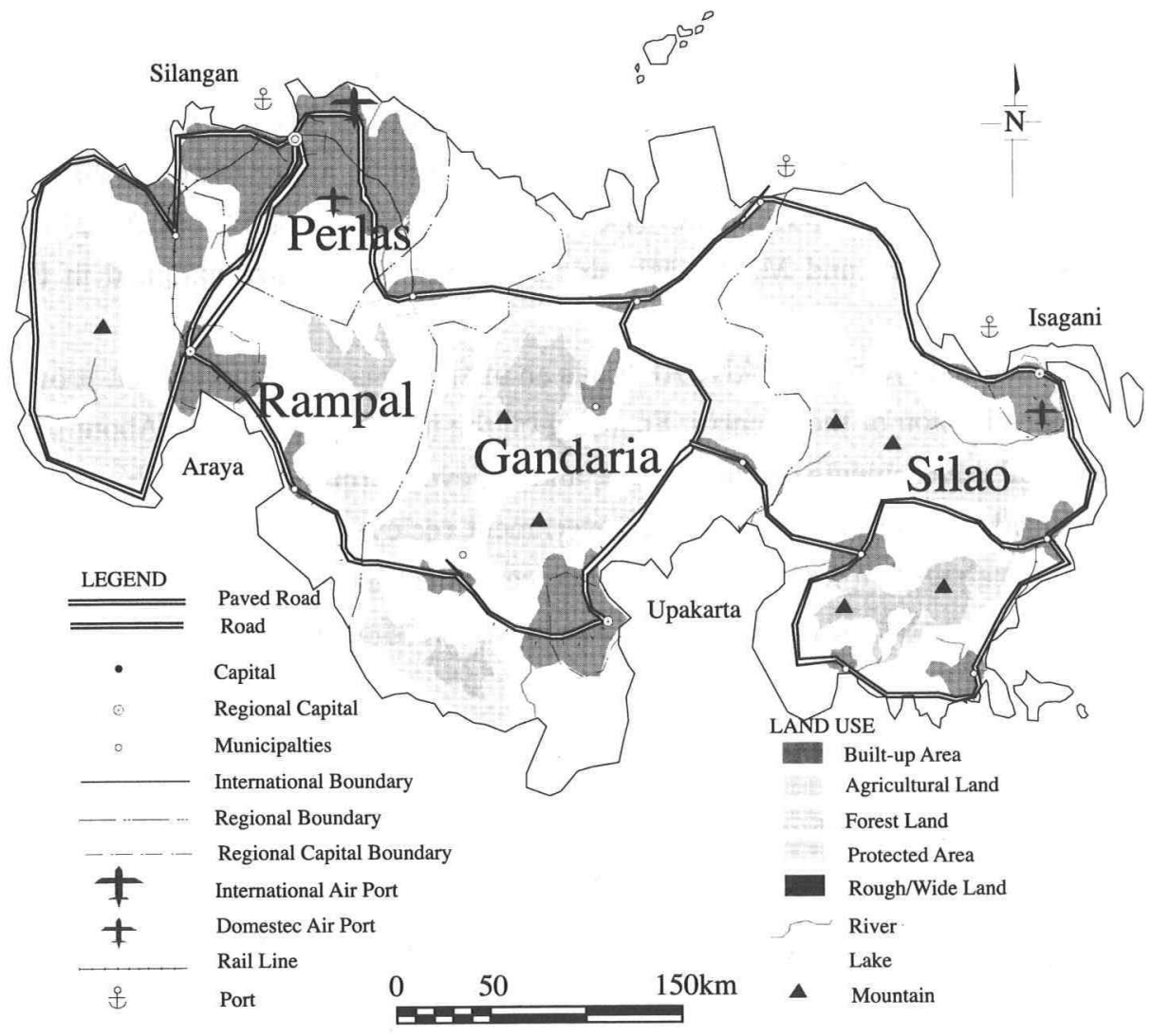

Figure 3 TOPOGRAPHY of pangaea country 


\section{Structure of Role Playing Gaming Model}

Design of gaming model is how to formulate confrontation or opposition and cooperation process in a game educing from the real one. Gaming model is constructed with role of players and procedure under the abstract framework of dynamics and activities. Especially, the theme of PANGAEA is closely concerning to planning formation processes on long-range public investments, thus the governmental role players, each of who has its own initiative and the financial constraints, decide the investment amounts for the projects on regional development and environmental treatment, by following the designed procedures for planning and coordination. There are three kinds of projects in PANGAEA : the first ones which the central government decides independently, the second ones which regional governments independently and the third ones which the regional governments decide but are subsidized by the central government. Some of the projects are available for foreign loans.

In the central government of case 1 and 3 , there is PC : Planning Commissioner whose role is to control the long-range financial balance by dealing with tax affairs, long-range financial forecast and loans-affairs. Besides, there are MDI : Minister of Development \& Infrastructure who is given the broad authority to deal with the projects on regional development matters, and MEN : Minister of Environment and Natural Resources to deal with the environmental projects. The power balance between the both roles would be a key factor to succeed with the sustainable development. As same as above cases, in case 2, PC, MIA: Minister of Industry and Agriculture and MPW : Minister of Public Works are assigned in the roleplaying gaming.

The governmental system in PANGAEA has an institutional 'parameter' that provides the degree of centralization of the country. Focusing on the income tax system. About the incom tax, the regional governments decide its rate, and recieve its total amounts. But the distribution rate is decided uniformly, the central government recieves the tax revenue, based on it. Therefore, the distribution rate functions as the centralization parameter.

The roles and number of players with three cases are shown below (Table. 2):

\section{Computer Simulation Model}

The simulation model is thus designed to reflect such trade off between development and environment, as well as sustainability decided by the volume, spatial and time allocation, and resource/energy efficiency of development. 10 sub-sectors and 8 areas that are mutually related and influenced in very complex manners construct the model. It is described as a system dynamics model with near 1,000 variables by using Microsoft Visual BASIC. The sub-sectors and their components are listed in Figure 4. 
Evaluation of Defferent Planning Systems in Regional Substainable Development using Simulation \& Gaming

Table 2 Role System in PANGAEA

Case 1 : Centralized Planning System with Sector-oriented Planning

Case 3 : Decentralized Planning System with Local Initiatives

National government

Player 1: $\quad$ Planning Commissioner

Player 2: $\quad$ Minister of Development \& Infrastructure

Player 3: $\quad$ Minister of Environment and Natural Resources

\begin{tabular}{|c|c|c|c|}
\hline \multicolumn{4}{|c|}{ Regional government } \\
\hline Player 4: & \multirow{2}{*}{$\begin{array}{l}\text { Metropolitan Governor } \\
\text { Regional Governor } 2\end{array}$} & Perlas and Sirangan & $\begin{array}{l}\text { (Capital Region) } \\
\text { (Region 2) }\end{array}$ \\
\hline Player 5: & & Rampal & (Region 2) \\
\hline Player 6: & Regional Governor 3 & Gandaria & (Region 3) \\
\hline Player $7:$ & Regional Governor 4 & Silao & (Region 4) \\
\hline \multicolumn{4}{|c|}{ City government } \\
\hline Player 8: & \multirow{3}{*}{$\begin{array}{l}\text { Mayor of Capital City } 2 \\
\text { Mayor of Capital City } 3 \\
\text { Mayor of Capital City } 4\end{array}$} & Araya & \multirow{3}{*}{$\begin{array}{l}\text { (Regional capital in Region 2) } \\
\text { (Regional capital in Region 3) } \\
\text { (Regional capital in Region 4) }\end{array}$} \\
\hline Player 9: & & Upakarta & \\
\hline Player 10: & & Isagani & \\
\hline \multicolumn{4}{|c|}{ Citizen group or NGO } \\
\hline Player 11: & CiTizen Group 1 & \multicolumn{2}{|c|}{ Perlas and Sirangan (Citizen group in Capital Rgion) } \\
\hline Player 12: & CiTizen Group 2 Ram & Rampal & (Citizen group in Capital Rgion 2) \\
\hline Player 13: & CiTizen Group 3 Gand & Gandaria & (Citizen group in Capital Rgion 3) \\
\hline Player 14: & CiTizen Group 4 Silao & Silao & (Citizen group in Capital Rgion 4) \\
\hline Player 15: & CiTizen Group 5 Aray & Araya & (Citizen group in City 2) \\
\hline Player 16: & CiTizen Group 6 Upal & Upakarta & (Citizen group in City 3 ) \\
\hline Player 17: & CiTizen Group 7 Isaga & Isagani & (Citizen group in City 4 ) \\
\hline
\end{tabular}

Case 2 : Centralized Planning System with Integrated Planning

National government

Player 1: $\quad$ Planning Commissioner

Player 2: $\quad$ Minister of Industry and Agriculture

Player 3: $\quad$ Minister of Public Works

Regional government (same as case $1 \& 3$ )

City government (same as case $1 \& 3$ )

Citizen group or NGO (same as case $1 \& 3$ )

It is assumed that in the beginning the national economy of this country "Pangaea" stands at a quite low level and is still in the developing stage. Therefore, the major driving force for the take off the country's economy is the foreign direct investments (SUB/GLOB). In order to attract them, infrastructure improvement such as national (trunk) road network building, trade port construction, stable power supply systems are indispensable (SUB/INFR). On the other hand, environmental protection policy has to be introduced at a very early stage of economic development, because the recovery of once seriously desrupted environment would be very costly or might be impossible over generations (SUB/ENV). Strict environmental 
Kanagae, Kaji and Kaneda

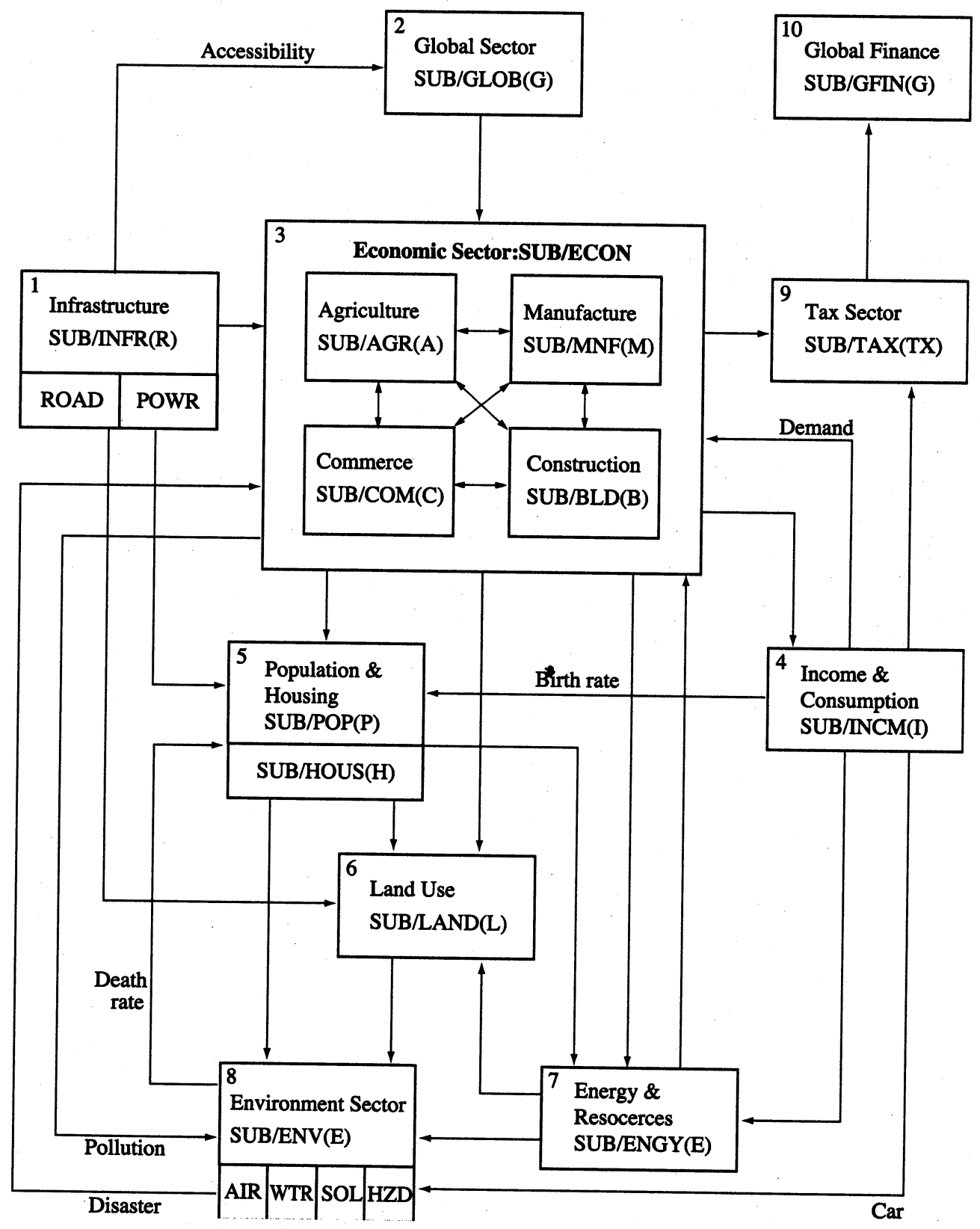

Figure 4 Diagram of PAN/DECS model 
protection measures, however, would discourage foreign direct investments (SUB/GLOB).

Economic activities of Pangaea are grouped into 4 major areas, namely, (i) agriculture, (ii) manufacturing, (iii) commerce and tourism, and (iv) construction (SUB/ECON). The supply demand gap of the agricultural products encourages or discourages opening of new farmlands and improvement of agricultural productivity by irrigation/modernization. It brings about changes in the land use pattern, turning waste and forestlands to farmlands. It also requires more resource and energy consumption.

Development of basic industries either by the government or by foreign direct investment increases production of basic industrial material components for domestic supplies and exports. It contributes to generate small and medium scale industries as subsidiaries of such basic industries, and greatly helps the country's economies to take off. In order to realize industrial development, tax policies as well as labor, energy, land and other resources supplies need to be attractive enough for the basic industries to locate.

Commercial activities and tourism development is another very effective way to accelerate economic growth. As in the case of industrial development, it generates construction demands and job opportunities. Tourism promotion invites foreign tourists as well, and they contribute to increase consumption of the domestic products and services. Tax revenue from commercial and tourism activities is as important as the industrial activities.

Development of all above three groups of economic activities depend on the infrastructure development, such as better accessibility for commodity distribution and stable supply of power, water, land and other resources. It creates lots of construction demand in public works and private sector developments, and employs construction workers. On the other hand, it consumes lots of energy and resources, and creates lots of potential hazards. Such adverse effects should be carefully controlled by balanced inputs in time and space allocation fully considering the carrying capacity of the environment, and also by some appropriate counter measures to minimize them.

Each region has 2 areas; one having the regional capital is of an urban nature and the other surrounding the former is of a suburban nature in case of (1) Perlas, and of a rural nature in the rest of the regions. The model deals with the competitiveness in development between those two areas of different natures. Reduction of income disparities and a balanced development of the country in terms of the spatial allocation should be a priority strategy for achieving the national development target (SUB/INCM). It is also true from the environmental point of view that a balanced development is effective for environmental consevation. If the development input is distributed in a wider area, the risk of disrupting the nature beyond its tolerance level would be lessened.

Natural hazards are another crucial aspect to be considered in securing sustainability of development. Magnitude of the damages caused by natural disasters is closely related to the 
land use pattern (SUB/LAND). Denuded forests by development activities and squatter settlements created even in hazardous places by the migrants flowing into the cities (SUB/ POP) over their accommodating capacity are the major factors for making the damages worse once the disasters occur.

The model deals with the financial aspects of the national as well as local governments (SUB/TAX). Tax policies are an essential factor for deciding the scale of local revenue base available for development investments. The local financial resources from taxes have to be partly transferred to the national treasury according to the rate specified by the tax contribution policy. This contribution together with the national tax revenue and loans make up the national accounts available for project inputs at the national level. The national government' s expenditure for development inputs covers subsidies and repayment of loan interests, not to mention the national projects cost. In this way, the money flows go back to the local governments. Over investments and debts beyond the repayment ability of the government would eventually ruin the foundation of the country's economies, although economic growth maight be achieved seemingly faster up to a certain level (SUB/GFIN). A balanced financial planning would also be pertinent for sustainable development.

All these phenomena described above are integrated in the model that would simulate the player's decisions for their development plans by way of project investments and development policy choices, using very complex chains of causal relation among the components in the respective sectors of the model.

The block diagram (Figure 4), describing the sectors and relations among them is attached for providing an overall picture of the model. The description of the respective sectors are presented at the following section.

\section{Financial system and projects in PANGAEA}

In the financial aspect of project investments in PANGAEA, there are two types of sources for financing in investments; namely :

tax revenue both at the national and local levels and loans (debts).

The tax system of PANGAEA consists of the national and local taxes, as well as the local tax contribution to the national treasury:

(1) Car tax (National tax)

(2) Household income tax \& production tax (Local taxes)

(3) The production tax rate is actually the base tax rate for production in three sectors

(4) Tax contribution to the national treasury

(5) Local budget for project investments

(6) National budget for project investments 
(7) Subsidies: The national government provides subsidies to the cost local projects. The subsidy share of the authorized investment varies according to the institutional arrangements. In cases 1 and 2, the subsidy would be provided to cover $70 \%$, and in case $3,30 \%$ of the individual local project cost at the maximum. In other words, the local government should cover the minimum $30 \%$ (in cases 1 and 2 ) or $70 \%$ (in case 3 ).

(8) Loans: Loans can be utilized to finance project investments as well. Loans are a financial matter solely handled by the nationa government and are often applied to big national projects. Besides the loans for project investments, there is the emergency relief loan that would be automatically made available by foreign countries and agencies when a disaster and its damages are greater than a certain scale. This type of loans would be provided for the sole purpose of emergency relief and reconstruction.

There are two groups of projects, that is, national projects and local projects. Planning Coordinator and Ministers make in investments in the national projects. Local governments make investments in the local projects. The projects can be selected by the respective roles. It should be noted that the projects that can be selected by the players differ from case to case, according to the difference in their institutional arrangements. The list carries the projects with their number, contents, dimension, unit cost, whether the project is available both as the national and local project or not, and implementing office (role), under the respective sector for the convenience of players.

When the unit cost has a value, it means that the project in question would be input eventually reflected in the final demand in Income and Consumption Sector/INCM. When the national subsidy is applied, $70 \%$ of the authorized (not necessarily the "requested") subsidy project units will be covered by the subsidies in Cases 1 and 2, and $30 \%$ of them in Case 3 . "MInistries" columns in the National Projects List and Subsidies column in the Local Projects List tell that the relevant ministries an finance the marked projects.

\section{Results of simulation \& gaming}

The authors had an opportunity to hold an experiment in which 150 participants had made three different organizational settings and performed simulation \& gaming parallel at Okinawa University on November 1996 using PANGAEA version $3^{2}$. It took around 5 days. This training was held in LEAD Okinawa session, and all of participants from 18 countries had a high quality of concern on environmental matters. Tax Distribution of centralized government system in case 1 and 2 were defended to central government had $50 \%$ and local government had $50 \%$. In case 3 was defined $25 \%: 75 \%$.

Performance of the simulation \& gaming are shown in Table 3 and 4.

In case 1 , all of the central government players didn't take any risk to start large-scale 
development projects. As a result, Table 3 show that population increasing level is good in the early year but increased on later. Compare with increasing ratio of population, GDP did not increase. Powered centralized government tried to protect becoming bad condition of environment. They made their slow economic expansion plan. The income level had not been grown up under $3 \%$ annually for 20 years. On the other hand, the deforestation and hazardous place had held bad minimally.

In case 2, one of the reason is PC (Planning Commissioners) players selected the finance expansion policy. According to this policy, both Ministry players had taken the investment concentrates on the first five years. A boom has come for the first 5 years, but after then the economy has overshot. As the result, the highest economic growth had achieved but paid heavily for allowing the worst of the sprawl and deforestation during the boom. The forestland had been smallest in the three gaming results. Chaotic behavior of case 2 can be caused by over-concentration of the power into the central government. Such as the well-known BEER GAME, this over-investment had triggered the chaos to their society. Not only socio-economical view but aspect of environment and risk, they made extreme plan which run extremity situations like rapid explosion of population, over concentration in national capital city, high traffic jam and radical change of number of hazardous place. This case is not stable for gentle development, but this case is similar to real development.

In case 3 , the economy had grown steadily, still lower than case 1 . The efforts of the local government players to promote family planning had worked to the population control

Table3 Results of simulation \& gaming

\begin{tabular}{lrrrrrc}
\hline \multicolumn{1}{c}{ Year } & AK30 & \multicolumn{1}{c}{ AK35 } & \multicolumn{1}{c}{ AK40 } & \multicolumn{1}{c}{ AK45 } & \multicolumn{1}{c}{ AK50 } & UNIT \\
\hline Population/CASE 1 & 107,688 & $\mathbf{1 1 4 , 8 2 0}$ & 126,206 & 140,148 & 156,236 & 1,000 persons \\
Population/CASE 2 & 107,688 & 116,942 & 127,433 & 138,160 & 150,342 & 1,000 persons \\
Population/CASE 3 & 107,688 & 114,971 & $\mathbf{1 2 3 , 6 0 1}$ & $\mathbf{1 3 2 , 4 5 6}$ & $\mathbf{1 4 2 , 8 0 3}$ & 1,000 persons \\
\hline GDP/CASE & 197,741 & 121,776 & 134,320 & 150,815 & 167,738 billion shell $^{* 3}$ \\
GDP/CASE & 297,741 & $\mathbf{1 9 0 , 2 4 5}$ & $\mathbf{2 1 1 , 3 8 1}$ & $\mathbf{2 5 1 , 0 7 6}$ & $\mathbf{2 7 9 , 0 0 0}$ billion shell $^{* 3}$ \\
GDP/CASE & 397,741 & 123,697 & 157,129 & 207,830 & $\mathbf{2 5 7 , 5 6 8}$ billion shell \\
\hline Hazardous place/CASE 1 & 931 & $\mathbf{1 , 4 2 4}$ & $\mathbf{2 , 3 8 3}$ & $\mathbf{2 , 2 3 7}$ & $\mathbf{3 , 6 2 2}$ & Places \\
Hazardous place/CASE 2 & 931 & 16,581 & 17,468 & 2,288 & $\mathbf{3 , 4 5 6}$ & Places \\
Hazardous place/CASE 3 & 931 & 2,590 & 4,021 & 3,536 & 5,734 & Places \\
\hline Developed Land/CASE 1 & 8,461 & $\mathbf{1 0 , 3 6 1}$ & $\mathbf{1 1 , 7 6 4}$ & $\mathbf{1 4 , 6 4 8}$ & $\mathbf{1 6 , 6 4 0}$ & $\mathrm{km}^{2}$ \\
Developed Land/CASE 2 & 8,461 & 25,336 & 26,986 & 28,678 & 30,647 & $\mathrm{~km}^{2}$ \\
Developed Land/CASE 3 & 8,461 & 11,248 & 13,362 & 16,611 & 19,566 & $\mathrm{~km}^{2}$ \\
\hline Forest Area/CASE 1 & 86,104 & $\mathbf{8 8 , 7 1 0}$ & $\mathbf{8 7 , 7 1 3}$ & $\mathbf{8 5 , 9 1 7}$ & $\mathbf{8 4 , 4 2 5}$ & $\mathrm{km}^{2}$ \\
Forest Area/CASE 2 & 86,104 & $\mathbf{7 4 , 5 5 8}$ & 67,989 & 70,243 & 62,628 & $\mathrm{~km}^{2}$ \\
Forest Area/CASE 3 & 86,104 & 84,680 & 83,000 & 80,832 & 76,544 & $\mathrm{~km}^{2}$ \\
\hline
\end{tabular}


Evaluation of Defferent Planning Systems in Regional Substainable Development using Simulation \& Gaming

Table 4 Growth Ratio and Growth Magnification/Results

(Base year AK30 GDP=1)

\begin{tabular}{|c|c|c|c|c|}
\hline Growth rate & 5 years & 10 years & 15 years & 20 years \\
\hline $2 \%$ & 1.104 & 1.219 & 1.346 & 1.486 \\
\hline $3 \%$ & 1.159 & 1.344 & 1.558 & 1.806 \\
\hline $4 \%$ & 1.217 & 1.480 & 1.800 & 2.191 \\
\hline $\mathbf{5 \%}$ standard & $\mathbf{1 . 2 7 6}$ & $\mathbf{1 . 6 2 9}$ & $\mathbf{2 . 0 7 9}$ & $\mathbf{2 . 6 5 3}$ \\
\hline $6 \%$ & 1.338 & 1.791 & 2.397 & 3.207 \\
\hline $7 \%$ & 1.403 & 1.967 & 2.759 & 3.870 \\
\hline CASE 1 & 1.246 & 1.374 & 1.543 & 1.716 \\
\hline CASE 2 & $\mathbf{1 . 9 4 6}$ & $\mathbf{2 . 1 6 3}$ & $\mathbf{2 . 5 6 9}$ & $\mathbf{2 . 8 5 4}$ \\
\hline CASE 3 & 1.266 & 1.608 & 2.126 & $\mathbf{2 . 6 3 5}$ \\
\hline
\end{tabular}

effectively, as the result ; the income level did not be inferior to case 1 so much. Moreover, the deforestation had controlled bette than case 1. Compare with only this three cases, case 3 is the most successful in the meaning of the sustainable development. Because established governing (power) group will not take risks of nation divide and national dispute, most of all the developing countries did not nor could not chose decentralized planning systems independent from governance systems of entire region and country.

\section{Conclusion}

In PANGAEA, three types of the institutional setup are prepared, namely ; (1) sectoral and compartmentalized planning system under a strong initiative of the central government ; (2) sectoral but integrated planning system under a strong initiative of the central government ; and (3) decentralized planning system is strong local initiatives. PANGAEA prepares these cases of institutional setup to be selected and tried by the players.

Although the details of the gaming varies from one case to another, the general flow of the game which is common in all cases can be described as below:

At the beginning of the gaming, the players will be divided into three groups representing three cases of institutional arrangements. Then, they will be assigned several roles to be performed under the specific institutional setup. The three sets of institutional arrangements are as follows:

Three groups, which employ the respective planning systems as above, will formulate their respective regional plans of 20-year term for the country "PANGAEA" with the limitations imposed by the country's budgetary scale. The players can retrieve necessary data 
for their plan formulation from the database installed in the computer.

In the process of the plan formulation, the role players have to follow some set rules of the gaming for negotiation and collaboration among themselves, which would be both common and peculiar with cases. When they reach the finalization stage of their plan formulation, their plans will be authorized for implementation.

The authorized plans will make the input for computer simulation. First, the simulated results on the economic growth and environmental changes over the first 10-year term will be put out. At this stage, if the players involved in the plan formulation judge that the output is far below the intended levels, they are allowed to make some minor modifications in their plan. The modified plan will again be run for the remaining 10-year term, for forecasting the output of the full 20 -year term of the plan. If the interim output is more or less satisfactory, the plan can be run for the rest of the term without any modification.

When all three groups get the final results of the picture of 20 years after, each group analyzes the output and evaluates their planning among themselves. Then, all three groups get together and evaluate the results with other. The latter session is particularly useful for analyzing the respective outputs in terms of the different features of institutional arrangements. The avaluation of three setups, namely changes in the economic and ecological systems in managing the process of making development sustainable will be the concluding and also important part of this planning.

Finally, We cannot conclude clealy with general answer from the results of this simulation \& gaming, because cases of simulation \& gaming experiments are not enough for judging that decentralization is suited for sustainable development every time. But the results of our simulation \& gaming experiments shows that in the centralized cases the actions of the central government players are very sensitive to the whole result of the sustainability. On the contrary, in the decentralized case, the local governmental players can manage their own regional sustainability autonomically, so the total 'sustainability' can be archived consequently. The results of our experiment give us some suggestions about how to redesign the public governmental planning systems to be suitable for the sustainable development age, especially for managing investment for both of development and environmental treatment, as well as effectiveness to gaming simulation.

\section{Notes}

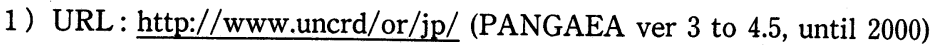

URL: http://www.pangaea.sfc.keio.ac.jp/ (PANGAEA2000 ; from 2000)

2 ) Update version is PANGAEA2000, PANGAEA ver.1 (1994) prototyping model, PANGAEA ver.2 (1995) Internet model, PANGAEA ver.3 (1996) the Internet model, PANGAEA ver.4 (1997) the Internet model with multi-severs, PANGAEA ver.4.5 (1999) modified type of the Internet model with multi-servers, PAN- 
GAEA2000 (2000) Advanced model.

3 ) In PANGAEA, currency unit is shell.

\section{References}

The World Commission on Environment and Development (WCED) 1987. Our Common Future.

Pezzey, J. 1989. Economic Analysis of Sustainable Growth and Sustainable Development.

Firman, T., 1992, The spatial pattern of urban growth in Jawa 1980-1990, Bulletin of Indonesian Economic Studies.

World Bank 1993, The East Asia Miracle-Economic Growth and Public Policy, embargo.

World Bank 1994, Environment Department Working Paper No. 15.

Firman, T., \& Dhaemapatini L., 1994, The challenges to sustainable development in Jakarta Metropolitan region, HABITATINTERNATIONAL, vol. 18, no. 2.

Haq. M. 1995. Reflections on Human Development. Oxford.

UNCRD editions. 1995. PANGAEA ver. 2 manual book 1 to 5. United Nations Centre for Regional Development, Nagoya, Japan

Kanegae H. and Kaneda T., 1995, A Gaming Simulation for Sustainable Development Planning, Quotation of presentation papers of 7th Conference Japan Association of Simulation And Gaming, JASAG, p. 86-91.

Kanegae H. and Kaneda T., 1995/96, A Gaming Simulation Model for Training in Sustainable Development and Planning, Regional Development Studies, UNCRD, Vol. 2.

UNCRD editions. 1996. PANGAEA ver. 3 manual book 1 to 3. United Nations Centre for Regional Development, Nagoya, Japan

UNCRD editions. 1998. Training Material Series No.2. United Nations Centre for Regional Development, Nagoya, Japan

Hidehiko KANEGAE, Hideki KAJI and others. 1998. A study on new gaming simulation for Region Planner Training on Regional sustainable development planning of developing countries, PANGAEA version 2, 1997. Journal vol. 8 no. 1, Japan Association of Simulation And Gaming.

Hideki Kaji. 1998, "Planning Dimensions of Sustainable Development", UNCRD discussion paper series No. 93-3

Hidehiko KANEGAE, and Hideki KAJI. 1998, Simulation and Gaming in regional planning, FINAL REPORT, RISK ASSESMENT AND MANAGEMENT : Planning for an Uncertain Future, PROCEED. INGS CONGRESS 1997, International Society of City and Regional Planners (ISOCARP), ISBN 90-7552409-9

Hidehiko KANEGAE and Hideki KAJI. 1999. A Gaming Simulation for Regional Sustainable Development: PANGAEA, Proceedings of the 6th International Conference of Computer in urban planning \& urban management 1999/6th CUPUM '99 \& ISAGA, Franco Angeli ISBN 88-464-1685-6 